\title{
FIRST RESULTS FROM A STUDY ON THE EFFICACY OF USING VIRTUAL REALITY (VR) TO TEACH TRUSS MECHANICS
}

\author{
Ryan Banow and Sean Maw \\ University of Saskatchewan \\ ryan.banow@usask.ca, sean.maw@usask.ca
}

\begin{abstract}
In 2018, the University of Saskatchewan's College of Engineering established a Virtual Reality Teaching and Cloud-based Learning (or ViRTCL) lab featuring three high-performance HTC Vive Pro VR stations that will be used for day-to-day teaching and for pedagogical research. Also during 2018, we worked with local start-up Sprockety Ventures Inc to develop custom VR software (called TrussVR ${ }^{\mathcal{O}}$ ) that is designed to help students learn about trusses. In the Fall term of 2018, a pilot study began to evaluate the learning efficacy of Truss $V R^{\mathcal{O}}$. This paper conveys the initial quantitative results of the pilot study.

For this study, TrussVR ${ }^{\odot}$ existed as a 3-module lab experience. The first module exposed students to various types of trusses, and allowed students to rapidly test the trusses with applied forces of their choice. The trusses "responded" by showing the qualities of their internal forces including intensities of compression and tension, as well as zero-force members (ZFMs). The second module consisted of two parts. The first showed the distribution of forces in the two-force members (2FMs) of a truss and asked students to apply an external load that would create those internal forces. The second did the reverse i.e. it displayed a truss and an external force and asked students to label the 2FMs with C (compression), $T$ (tension), or $Z$ $(Z F M)$. The third module was a design module where students constructed a bridge truss and tested it.

In September 2018, students were recruited from the first-year GE 124 Engineering Mechanics I (Statics) class to take part in a pilot study on TrussVR ${ }^{\odot}$. Ethics clearance had been granted by the Behavioural REB of the University of Saskatchewan. More than 160 students volunteered. They all completed a "pre-survey" before the lecture content on trusses began. The pre-survey explored issues of knowledge, skills, and attitudes as they pertained to trusses and VR. The study participants were then randomly divided into three groups: no truss lab, conventional truss lab (Pasco $^{\odot}$ construction set), and TrussV ${ }^{\odot}$ lab. During the time of the course when study non-participants completed the $\mathrm{Pasco}^{\odot}$ lab, the study participants completed either no lab, the Pasco ${ }^{\odot}$ lab, or the TrussVR ${ }^{\odot}$ lab. After the lab sessions for trusses were completed, all study participants completed a "post-survey" that re-examined knowledge, skills, and attitudes towards trusses. Furthermore, exam marks of the study participants for truss and frame questions were examined for statistically significant differences. Finally, in mid-February, study
\end{abstract}

participants redid the post-survey to examine any differences between conditions in shorter-and longer-term changes in knowledge, skills, and attitudes.

Initial results focus on any statistically significant differences between pre, post, and distant-post results on the surveys, as well as on exams, between and within experimental groups. Given how the exams were marked, we were also able to look for patterns and differences in different sections of answers in addition to overall scores. We anticipated that there may be differences in attitudes towards trusses between the three experimental groups (no lab, Pasco ${ }^{\odot}$ lab, TrussVR ${ }^{\odot}$ lab). There may also be differences in skills and knowledge.

Keywords: virtual reality, trusses, statics, mechanics, teaching and learning, pilot study

\section{INTRODUCTION}

The potential value of using virtual reality (VR) in entertainment has been pursued since the 1960s [14]. The opportunity to create an artificial world and work within it also has the potential to address a number of challenges in the world of education. It has been recognized for some time now that in virtual reality dangerous situations can have minimal consequences, costly activities can involve lower financial burdens, and activities that are "impossible" in reality, can become possible in virtual realities [16]. This is especially true with complex spatial problems e.g. [10]. VR also holds potential for students with mobility challenges, as they now have the possibility of virtually visiting sites anywhere around the world [15].

These scenarios are especially relevant to engineering education, which often can involve dangerous concepts or expensive experiences. With many technically challenging concepts to teach, the options that VR offers can allow for creative new ways of teaching. This potential was noted well before modern hardware and software tools allowed VR to start realizing its potential e.g. [16].

Only in recent years, with the advent of equipment such as the Oculus Rift (www.oculus.com), the HTC Vive (www.vive.com), and Google VR glasses (vr.google.com), has this potential begun to be realized. As the cost of VR infrastructure has fallen and as the prevalence of VR software has risen, accessibility has increased dramatically. 
It has often been stated that learning with VR is more effective than learning by more conventional means e.g. [1, $6,14,15,16]$. However, hard evidence in the literature is difficult to find. Very few rigorous studies have been carried out, especially ones that distinguish what a learner is doing in VR as opposed to the use of VR itself. The novelty of VR can be a confounding factor that may overstate its value [14].

VR's educational advantages are purported to primarily involve active learning, higher levels of engagement, and/or embodied cognition. Active learning can be defined as any activity which meaningfully engages the learner in thinking about what they are doing e.g. [18], as commonly happens in VR. This can lead to better thinking [3]. In [18], Prince makes the point that active learning is more than just learning activities. These activities need to be tied to important learning outcomes and they need to encourage deep engagement. Findings in the field of cognitive psychology suggest that additional information processing after initial learning is key for long-term retention [19]. In embodied cognition, the theory is that we make sense of the world through our body's interaction with it, which VR readily provides e.g. [13]. These characteristics, combined with VR's unique abilities to dampen danger, save money, and make the impossible possible, give VR a potentially unique niche in the future of engineering education.

Recognizing this, the University of Saskatchewan's College of Engineering recently undertook a pilot project to explore the potential of VR in engineering education. A physical "VR teaching lab" was established with multiple VR stations, and software was engineered to assist in the teaching of a core topic in first-year. The topic was trusses, popularly found in first-year statics courses. Although some technical advice in the literature is becoming dated regarding best practices for VR software development e.g. [2], it still holds true that one should identify an appropriate application for VR, and that the software should supplement traditional teaching. More recent reviews have highlighted concerns about the state of the quality of instructional design in VR environments [14].

Truss problems are common in statics courses, and are typically solved using the Method of Joints and/or the Method of Sections. These are not particularly difficult methods, but they are time consuming. As a result, students can spend up to 30 minutes solving one loading scenario for a simple truss. Rarely do students re-evaluate the truss under different loading conditions, given the timeconsuming nature of the task. As a result, few students develop a "feel" for a given type of truss and how it behaves under a variety of loading conditions. The time consuming calculations discourage the development of such intuition.

Software tools targeting this learning gap do exist. Hubing et al [7] developed a computer-based teaching tool for truss analyses but their software did not facilitate the creation and testing of truss structures. Karweit [9] created
"Bridge Designer" which does much of what TrussVR ${ }^{\odot}$ does, only in 2D. This software was suspected to be very effective in enhancing the performance of trusses in a competitive bridge design contest.

Working with a local software development firm (Sprockety Ventures, www.sprockety.com), the authors and their team developed TrussVR ${ }^{\odot}$. This software package allows students to quickly build and test trusses in VR. In applying virtual loads to these virtual trusses, students are shown (via colour coding) which two-force members (2FMs) are in tension, or compression, or are zero-force members (ZFMs). By hiding the mathematics, the students can focus on what loads do to the truss and how the truss reacts. The primary learning objective is to enhance the abilities of students to predict how a truss will react to external loads, and to determine which external loads will create a given set of internal forces in a truss' members. Figure 1 illustrates a truss from TrussVR ${ }^{\circ}$.

For the purposes of this pilot study, three modules were created in TrussVR ${ }^{\circ}$ to engage students in learning about trusses. The first module rewards the students for looking at, and testing, a variety of different types of truss designs e.g. Howe, Pratt, Polynesian. The second module directly tests the ability of students to determine external loads that produce given internal forces, and vice versa. Feedback is provided for incorrect answers, to help inform future guesses e.g. if ZFMs are missed, a prompt encourages the student to look for them. The third module allows students to build truss bridges and test them. A "snap to grid" feature assists students in this task, similar to what students suggested to Kaufmann et al in [10]. The bridge design module situates Truss $\mathrm{VR}^{\odot}$ squarely in educational gaming, where positive long-term learning effects have been found [14]. However, the software also constitutes a VR simulation tool, the nature of which has been found to be effective when built upon conventional instructional methods [14] and when focused on facilitating practice. All three modules incorporate time limits to ensure that all students have the same duration of exposure to TrussVR ${ }^{\odot}$.

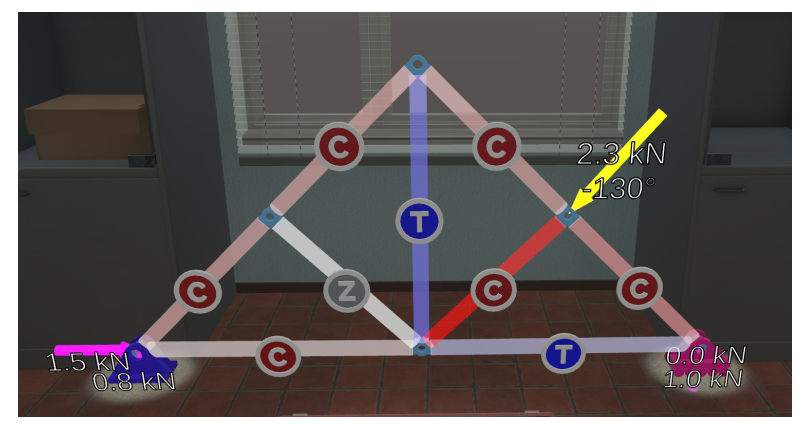

Figure 1. A sample truss from TrussVR ${ }^{\odot}$.

In the Fall of 2018, a randomized control trial pilot study was conducted with first-year engineering students at the University of Saskatchewan to see if, and how, TrussVR ${ }^{\circ}$ 
might enhance the learning of trusses. Using a positivist paradigm, the study involved mixed method surveys and test performance measures. This paper describes our study, including some of its initial quantitative findings. Very few studies of this kind have been previously reported (see $[5,6])$. In some respects, the most similar has been that of Madden et al [13] that involved 3 conditions (normal lab, desktop app, and VR app) with a pre/post assessment model employing isomorphic sets of questions. As the next section in this paper will show, our study had some similar features.

\section{METHODS}

The participants in this study were recruited from those enrolled in the Fall 2018 offering of first-year GE 124 Engineering Mechanics 1 (Statics). There were 440 students enrolled. We visited the class within the first month of the term and explained the study to the students and asked those interested in taking part to complete an online sign-up survey on SurveyMonkey. We received responses from 228 students.

Over one month later, three weeks prior to trusses being taught in the class, we emailed a SurveyMonkey link to the Pre-Survey to all of the signed-up participants. The PreSurvey contained the consent form and 45 questions in total. There was a mix of closed- and open-ended questions. There were questions on demographics, prior experiences with VR, Likert scale questions on interest, confidence, and excitement about learning trusses, a question asking participants to name as many trusses as possible, and a series of quiz-style questions to assess their prior knowledge and skills regarding trusses. The quiz questions were of five main types: identify the type of truss from a list of names based on an image of the shape (7 questions); given a diagram of a simple structure, identify if it is a truss or not (3 questions); given a diagram of a truss and a pattern of tension and compression, identify the joint and direction of the force (3 questions); and given a diagram of a truss with a force vector acting on a joint, identify whether each member is in compression, in tension, or is a zero-force member (3 questions). Since the students had not yet covered trusses in the course, it was expected that most students would have little prior knowledge of them. A total of 166 students fully completed the Pre-Survey.

After the Pre-Survey closed, we randomly assigned the participants into three experimental groups: $\mathrm{Pasco}^{\circ}$, No $\mathrm{Lab}$, and Truss VR ${ }^{\odot}$. The Pasco $^{\odot}$ group would complete the regular truss lab along with the students in the course that did not sign up to take part in the study. The Pasco ${ }^{\circ}$ lab is 2-3 hours long and involves students using a physical construction set to build and test a truss design (see pasco.com), after having calculated its behaviour. The No Lab group did not complete a lab related to trusses. Their truss lab was omitted from calculations of the students' final grades in the course. The TrussVR ${ }^{\odot}$ group would engage in a 25-min VR truss lab. During the same time period as the labs, there were approximately four 80 minute lectures related to trusses, for all students.

The Truss $\mathrm{VR}^{\odot}$ lab was conducted in software designed at the University of Saskatchewan in cooperation with Sprockety Ventures (www.sprockety.com). Truss $V^{\odot}{ }^{\odot}$ runs in Unity on HTC Vive Pro hardware. The goal of the software is to teach trusses and to allow users to quickly build and test truss shapes. The 25-minute lab experience involves five main stages: tutorial, testing common truss designs, identifying the joint and direction of a force that is acting on a truss, identifying the pattern of tension and compression in a truss, and building a bridge. Student grades were computed based on the latter four stages and were used as part of calculations of the final grades in the course. Biometric data was also collected on these participants as they used $\operatorname{Truss}_{\mathrm{VR}}{ }^{\odot}$, primarily to assist in improving the software.

Once all the $\operatorname{Pasco}^{\odot}$ and TrussVR ${ }^{\odot}$ labs were complete, participants were emailed a link to the Post-Survey. Each group received a slightly different survey, as there were unique feedback questions related to experiences with their specific intervention. There were 31 common survey questions. The survey contained repeats of the Likert scale questions on interest, confidence, and excitement about learning trusses, a question asking participants to name as many trusses as possible, and a series of quiz-style questions. The quiz-style questions were all based on the same trusses as the Pre-Survey, but the force locations and directions had changed. The Post-Survey closed with a series of 8 open-ended questions asking the students' opinions on the approaches to the teaching of trusses e.g. "What should we stop doing in the future regarding the teaching of trusses?" and "What is the hardest skill to learn when analyzing trusses?"

Two months later, participants were emailed a link to the Distant-Post Survey. This survey was 31 questions long and repeated the common questions from the Post Survey. Again, the quiz-style questions were based on the same trusses, but the forces had been changed. In-between the Post and Distant-Post Surveys, students also completed the final exam in the course. The final exam occurred 6 weeks prior to the Distant Post-Survey. The final exam contained one truss problem and one frame problem.

Once the Distant-Post survey was closed, we offered students in all three of the experimental groups the option to take part in any interventions that they missed. For example, No Lab group members were offered the opportunity to try $\operatorname{Truss}^{\circ}{ }^{\odot}$ and the $\operatorname{Pasco}^{\odot}$ lab. In addition, those that completed all three of the Pre, Post, and Distant-Post surveys were entered into draws for gift cards.

The University of Saskatchewan Behavioural Research Ethics Board provided ethics clearance for the study. 


\section{RESULTS}

As suggested by the title of this paper, these are early results. This paper will only report on closed-ended responses provided by the students, and the final exam analyses. The open-ended responses will be reported in a future paper. Please note that the quantitative data was analyzed using IBM SPSS Statistics 25.

\subsection{Questions on Interest, Confidence, and Excitement}

There were five questions on each survey regarding students' interest, confidence, and excitement about learning trusses. As seen in Table 1, responses were similar across all three experimental groups at the three time points. Mixed ANOVAs were run for each question and no statistically significant differences were found across the experimental groups.

Table 1: Likert scale responses on interest, confidence, and excitement

\begin{tabular}{|c|c|c|c|c|}
\hline Question & Group & $\begin{array}{l}\text { Pre } \\
(\mathrm{M} \pm \mathrm{SD})\end{array}$ & $\begin{array}{l}\text { Post } \\
(M \pm S D)\end{array}$ & $\begin{array}{l}\text { DistantPost } \\
(M \pm \text { SD) }\end{array}$ \\
\hline \multirow{3}{*}{$\begin{array}{l}\text { I am } \\
\text { interested } \\
\text { in trusses }\end{array}$} & $\begin{array}{l}\text { No Lab } \\
(\mathrm{n}=35)\end{array}$ & $3.86 \pm 0.60$ & $4.06 \pm 0.59$ & $3.49 \pm 0.95$ \\
\hline & $\begin{array}{l}\text { Pasco }^{\circ} \\
(\mathrm{n}=16)\end{array}$ & $3.63 \pm 0.62$ & $3.94 \pm 0.57$ & $3.25 \pm 1.07$ \\
\hline & $\begin{array}{l}\text { TrussVR }^{\odot} \\
(\mathrm{n}=35)\end{array}$ & $3.86 \pm 0.60$ & $3.86 \pm 0.73$ & $3.60 \pm 0.89$ \\
\hline \multirow{3}{*}{$\begin{array}{l}\text { I know } \\
\text { about } \\
\text { trusses }\end{array}$} & $\begin{array}{l}\text { No Lab } \\
(\mathrm{n}=35)\end{array}$ & $2.77 \pm 0.91$ & $4.00 \pm 0.42$ & $3.83 \pm 0.66$ \\
\hline & $\begin{array}{l}\text { Pasco }^{\circ} \\
(\mathrm{n}=16)\end{array}$ & $2.06 \pm 0.68$ & $3.94 \pm 0.44$ & $3.81 \pm 0.54$ \\
\hline & $\begin{array}{l}\begin{array}{l}\text { TrussVR } \\
(\mathrm{n}=35)\end{array} \\
\end{array}$ & $2.66 \pm 0.87$ & $3.94 \pm 0.48$ & $3.91 \pm 0.37$ \\
\hline \multirow{3}{*}{$\begin{array}{l}\text { I am } \\
\text { competent } \\
\text { in } \\
\text { analyzing } \\
\text { trusses }\end{array}$} & $\begin{array}{l}\text { No Lab } \\
(\mathrm{n}=35)\end{array}$ & $2.57 \pm 0.92$ & $3.94 \pm 0.54$ & $3.69 \pm 0.83$ \\
\hline & $\begin{array}{l}\text { Pasco } \\
(\mathrm{n}=16)\end{array}$ & $2.38 \pm 0.96$ & $3.81 \pm 0.83$ & $3.63 \pm 0.72$ \\
\hline & $\begin{array}{l}\text { TrussVR }^{\odot} \\
(\mathrm{n}=35)\end{array}$ & $2.40 \pm 0.81$ & $3.71 \pm 0.62$ & $3.60 \pm 0.81$ \\
\hline \multirow{3}{*}{$\begin{array}{l}\text { I am } \\
\text { excited } \\
\text { about } \\
\text { trusses }\end{array}$} & $\begin{array}{l}\text { No Lab } \\
(\mathrm{n}=35)\end{array}$ & $3.97 \pm 0.66$ & $3.60 \pm 0.85$ & $3.23 \pm 1.14$ \\
\hline & $\begin{array}{l}\text { Pasco } \\
(\mathrm{n}=16)\end{array}$ & $3.75 \pm 0.68$ & $3.50 \pm 0.97$ & $3.06 \pm 1.24$ \\
\hline & $\begin{array}{l}\text { TrussVR } \\
(\mathrm{n}=35)\end{array}$ & $3.86 \pm 0.77$ & $3.69 \pm 0.87$ & $3.31 \pm 0.80$ \\
\hline \multirow{3}{*}{$\begin{array}{l}\text { I find } \\
\text { truss } \\
\text { analysis } \\
\text { easy }\end{array}$} & $\begin{array}{l}\text { No Lab } \\
(\mathrm{n}=35)\end{array}$ & $2.94 \pm 0.42$ & $3.34 \pm 0.80$ & $3.29 \pm 0.79$ \\
\hline & $\begin{array}{l}\text { Pasco } \\
(\mathrm{n}=16)\end{array}$ & $2.75 \pm 0.58$ & $3.63 \pm 0.72$ & $3.06 \pm 1.00$ \\
\hline & $\begin{array}{l}\text { TrussVR }{ }^{\complement} \\
(\mathrm{n}=35)\end{array}$ & $2.91 \pm 0.45$ & $3.43 \pm 0.74$ & $3.23 \pm 0.69$ \\
\hline
\end{tabular}

Likert Scale from 1 = "Strongly Disagree" to 5 = "Strongly Agree"

\subsection{Quiz-Style Questions}

To analyze the quiz-style questions, we first grouped each of the sets of questions together and weighed each response equally. For example, for "identify the type of truss from a list of names based on an image of the shape" we came up with a total score for each student at each time point out of seven. After doing this, we noticed that despite creating the experimental groups randomly, our three groups performed very differently on the Pre-Survey. Therefore, to control for the students' initial results on the Pre-Survey, we calculated Post Gain (Post - Pre), DistantPost Gain (Distant-Post - Pre) and Retention (Distant-Post - Post) scores for each set of questions. These are the values we used in our analyses and they are reported in Table 2.

Table 2: Gain and retention scores for quiz-style questions

\begin{tabular}{|c|c|c|c|c|}
\hline $\begin{array}{l}\text { Question } \\
\text { Set } \\
\text { (\# of } \\
\text { possible } \\
\text { marks) }\end{array}$ & Group & $\begin{array}{l}\text { Post Gain } \\
(M \pm \text { SD } \\
\text { (n)) }\end{array}$ & $\begin{array}{l}\text { Distant-Post } \\
\text { Gain } \\
(\mathrm{M} \pm \mathrm{SD} \\
\text { (n)) }\end{array}$ & $\begin{array}{l}\text { Retention } \\
(M \pm S D \\
\text { (n)) }\end{array}$ \\
\hline \multirow{3}{*}{$\begin{array}{l}\text { Identify } \\
\text { Name of } \\
\text { Truss (7) }\end{array}$} & No Lab & $\begin{array}{l}1.4 \pm 1.6 \\
(\mathrm{n}=35)\end{array}$ & $\begin{array}{l}0.9 \pm 1.8 \\
(\mathrm{n}=35)\end{array}$ & $\begin{array}{l}-0.5 \pm 2.0 \\
(\mathrm{n}=35)\end{array}$ \\
\hline & Pasco $^{(0)}$ & $\begin{array}{l}0.7 \pm 2.2 \\
(\mathrm{n}=34)\end{array}$ & $\begin{array}{l}0.3 \pm 1.4 \\
(\mathrm{n}=20)\end{array}$ & $\begin{array}{l}-0.5 \pm 1.5 \\
(\mathrm{n}=16)\end{array}$ \\
\hline & TrussVR $^{\odot}$ & $\begin{array}{l}* 1.9 \pm 2.4 \\
(\mathrm{n}=51)\end{array}$ & $\begin{array}{l}* 1.8 \pm 2.9 \\
(\mathrm{n}=35)\end{array}$ & $\begin{array}{l}-0.4 \pm 2.5 \\
(\mathrm{n}=35)\end{array}$ \\
\hline \multirow{3}{*}{$\begin{array}{l}\text { Identify } \\
\text { if Truss } \\
\text { or Not (3) }\end{array}$} & No Lab & $\begin{array}{l}1.2 \pm 1.1 \\
(\mathrm{n}=35)\end{array}$ & $\begin{array}{l}0.9 \pm 1.3 \\
(\mathrm{n}=35)\end{array}$ & $\begin{array}{l}-0.3 \pm 0.5 \\
(\mathrm{n}=35)\end{array}$ \\
\hline & Pasco ${ }^{\circ}$ & $\begin{array}{r}1.5 \pm 1.2 \\
(\mathrm{n}=33) \\
\end{array}$ & $\begin{array}{l}1.2 \pm 1.4 \\
(\mathrm{n}=20)\end{array}$ & $\begin{array}{l}-0.2 \pm 0.8 \\
(\mathrm{n}=16)\end{array}$ \\
\hline & TrussVR $^{\mathbb{C}}$ & $\begin{array}{l}1.1 \pm 1.2 \\
(\mathrm{n}=51)\end{array}$ & $\begin{array}{l}0.9 \pm 1.1 \\
(\mathrm{n}=35)\end{array}$ & $\begin{array}{l}-0.3 \pm 0.6 \\
(\mathrm{n}=35)\end{array}$ \\
\hline \multirow{3}{*}{$\begin{array}{l}\text { Identify } \\
\text { Force } \\
\text { Joint and } \\
\text { Direction } \\
\text { (6) }\end{array}$} & No Lab & $\begin{array}{l}1.7 \pm 1.6 \\
(\mathrm{n}=35)\end{array}$ & $\begin{array}{l}0.0 \pm 2.0 \\
(\mathrm{n}=35)\end{array}$ & $\begin{array}{l}-1.7 \pm 1.7 \\
(\mathrm{n}=35)\end{array}$ \\
\hline & Pasco $^{(0)}$ & $\begin{array}{l}1.8 \pm 1.6 \\
(\mathrm{n}=33)\end{array}$ & $\begin{array}{l}-0.4 \pm 2.1 \\
(\mathrm{n}=18)\end{array}$ & $\begin{array}{l}-2.1 \pm 2.0 \\
(\mathrm{n}=16)\end{array}$ \\
\hline & TrussVR $^{\odot}$ & $\begin{array}{l}1.7 \pm 1.8 \\
(\mathrm{n}=50)\end{array}$ & $\begin{array}{l}0.6 \pm 1.9 \\
(\mathrm{n}=34)\end{array}$ & $\begin{array}{l}-1.0 \pm 2.2 \\
(\mathrm{n}=34)\end{array}$ \\
\hline \multirow{3}{*}{$\begin{array}{l}\text { Identify } \\
\text { members } \\
\text { in } \mathrm{C}, \mathrm{T} \text {, } \\
\text { or ZFM } \\
\text { (15) }\end{array}$} & No Lab & $\begin{array}{l}0.2 \pm 3.7 \\
(\mathrm{n}=35)\end{array}$ & $\begin{array}{l}0.3 \pm 3.7 \\
(\mathrm{n}=35)\end{array}$ & $\begin{array}{l}0.2 \pm 3.3 \\
(\mathrm{n}=35)\end{array}$ \\
\hline & $\left.\operatorname{Pasco}^{(}\right)$ & $\begin{array}{l}0.6 \pm 3.9 \\
(\mathrm{n}=32)\end{array}$ & $\begin{array}{l}1.8 \pm 3.5 \\
(\mathrm{n}=15)\end{array}$ & $\begin{array}{l}0.3 \pm 3.4 \\
(\mathrm{n}=14)\end{array}$ \\
\hline & TrussVR $^{\odot}$ & $\begin{array}{l}0.4 \pm 3.4 \\
(\mathrm{n}=50)\end{array}$ & $\begin{array}{l}1.0 \pm 3.3 \\
(\mathrm{n}=33)\end{array}$ & $\begin{array}{l}0.7 \pm 3.4 \\
(\mathrm{n}=33)\end{array}$ \\
\hline \multirow{3}{*}{$\begin{array}{l}\text { Total } \\
\text { Quiz } \\
\text { Score } \\
(31)\end{array}$} & No Lab & $\begin{array}{l}4.5 \pm 5.3 \\
(\mathrm{n}=35)\end{array}$ & $\begin{array}{l}2.2 \pm 5.2 \\
(\mathrm{n}=35)\end{array}$ & $\begin{array}{l}-2.3 \pm 4.1 \\
(\mathrm{n}=35)\end{array}$ \\
\hline & $\mathrm{Pasco}^{(}$ & $\begin{array}{l}4.6 \pm 5.0 \\
(\mathrm{n}=32)\end{array}$ & $\begin{array}{l}3.3 \pm 5.4 \\
(\mathrm{n}=15)\end{array}$ & $\begin{array}{l}-2.0 \pm 4.9 \\
(\mathrm{n}=14)\end{array}$ \\
\hline & TrussVR $^{\odot}$ & $\begin{array}{l}5.1 \pm 5.6 \\
(\mathrm{n}=50)\end{array}$ & $\begin{array}{l}4.3 \pm 5.8 \\
(\mathrm{n}=33)\end{array}$ & $\begin{array}{l}-0.9 \pm 4.6 \\
(\mathrm{n}=33)\end{array}$ \\
\hline
\end{tabular}

$* \mathrm{p}<0.05$, Shading indicates the best scores for each type and time point

There was a statistically significant difference between groups for Post Gain: Identifying the Name of Trusses as determined by a one-way ANOVA $(\mathrm{F}(2,117)=3.520, \mathrm{p}=$ 0.033). Post-hoc comparisons, using the Tukey HSD, indicated that the mean Post Gain score for the TrussVR ${ }^{\odot}$ group $(\mathrm{M}=1.94, \mathrm{SD}=2.36)$ was statistically significantly higher than the $\mathrm{Pasco}^{\odot}$ group $(\mathrm{M}=0.71, \mathrm{SD}=2.17)$. However, the No Lab group $(\mathrm{M}=1.40, \mathrm{SD}=1.58) \mathrm{did}$ not 
statistically differ from the other two groups. Figure 2 shows the mean scores for each group on this set of questions across the three time points.

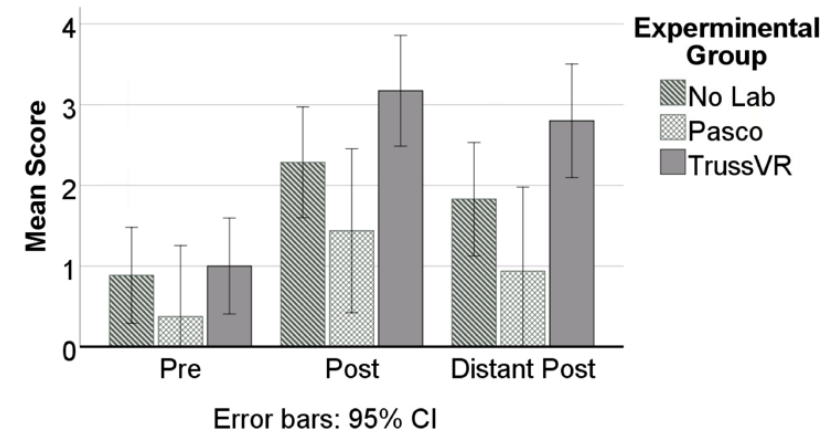

Figure 2: Identifying the name of trusses

There was also a statistically significant difference between groups for Distant-Post Gain: Identifying the Name of Trusses. We found this by running a one-way ANOVA, but since the assumption of homogeneity of variance was not met for this data based on Levene's $F$ test $(\mathrm{p}=0.024)$, we used Welch's $F$ test. The one-way ANOVA of Distant-Post Gain scores revealed a statistically significant difference, Welch's $(\mathrm{F}(2,54.96)=3.423, \mathrm{p}=$ 0.040) indicating that the three groups performed differently on these questions. Post-hoc comparisons, using the Games-Howell post-hoc procedure, indicated the mean Distant-Post Gain score for the TrussVR ${ }^{\odot}$ group (M $=1.80, \mathrm{SD}=2.87)$ was statistically significantly higher than the Pasco ${ }^{\circ}$ group $(\mathrm{M}=0.30, \mathrm{SD}=1.42)$. The No Lab group $(\mathrm{M}=0.94, \mathrm{SD}=1.85)$ did not statistically differ from the other two groups.

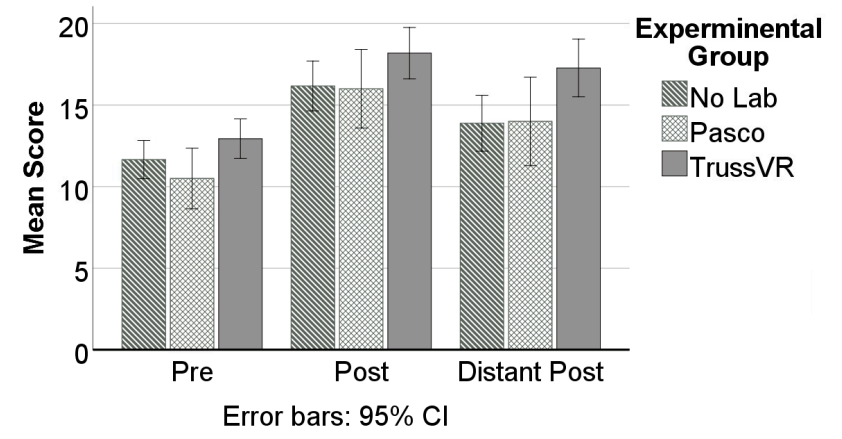

Figure 3: Total mean scores on quiz-style questions

No other measures of difference were found to be statistically significant. However, it is worth noting that the TrussVR ${ }^{\odot}$ group performed better on the majority of measures (9 out of 15). This was especially true on Retention. As shown by the shading in Table 2, the Truss VR $^{\odot}$ group demonstrated better retention on 4 out of 5 measures: Identifying the Name; Identifying Force Joint and Direction; Identifying C, T, or ZFM; and Total Quiz
Score. The TrussVR ${ }^{\odot}$ group also had the best Post Gain, Distant-Post Gain, and Retention scores when computing the total means on all quiz-style questions. Figure 3 shows the overall performance (total sum of all quiz-style questions) for each group across the experimental groups.

\subsection{Name as Many Trusses as You Can}

In each of the three surveys, study participants were asked to name as many types of trusses as they could. For example, "Howe", "Pratt", "simple", "space", and "roof", would all be acceptable answers. Figure 4 shows the results. The No Lab and $\mathrm{Pasco}^{\odot}$ groups both exhibited higher Post scores compared to their Pre scores, but in both cases, the Distant-Post scores went down. The TrussVR ${ }^{\odot}$ group, on the other hand, actually showed an increase from Post to Distant-Post.

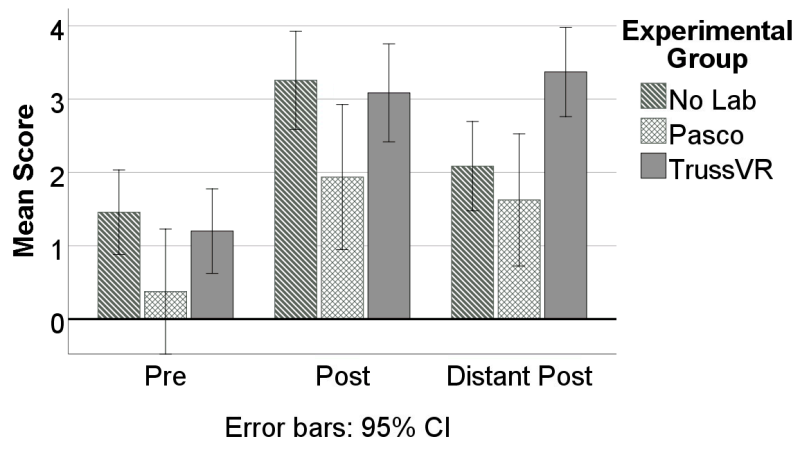

Figure 4: Name as many trusses as you can

There was a statistically significant difference between groups for Distant-Post Gain as determined by a one-way ANOVA $(\mathrm{F}(2,83)=4.395, \mathrm{p}=0.015)$. Tukey's HSD posthoc comparisons indicated that the TrussVR ${ }^{\odot}$ group $(\mathrm{M}=$ $2.17, \mathrm{SD}=2.29)$ performed significantly better than the No Lab group $(\mathrm{M}=0.63, \mathrm{SD}=2.28)$. The $\mathrm{Pasco}^{\odot}$ group $(\mathrm{M}=$ $1.25, \mathrm{SD}=1.65$ ) did not statistically differ from the other groups.

In addition, Retention was also significantly different as determined by a one-way ANOVA $(\mathrm{F}(2,83)=3.844$, $\mathrm{p}=$ 0.025). Using Tukey's HSD post-hoc comparisons we found that the TrussVR ${ }^{\odot}$ group $(\mathrm{M}=0.29, \mathrm{SD}=1.64)$ scored significantly higher than the No Lab group $(\mathrm{M}=$ $1.17, \mathrm{SD}=2.89)$. The Pasco ${ }^{\odot}$ group $(\mathrm{M}=-0.31, \mathrm{SD}=1.40)$ did not statistically differ from the other groups.

\subsection{Exam Results}

The course's final exam results for the Truss question and for the Frame question were examined in detail for each of the study participants. It was never likely that a short VR experience that focused on the noncomputational aspects of trusses would yield a measurable outcome on an exam focused on computation. However, 
there was a chance that the insights garnered from Truss VR ${ }^{\odot}$ could improve the abilities of students to set up the solution to a truss by enhancing tactics on free body diagram selections. As it happened, no such patterns were found.

\section{CONCLUSIONS AND DISCUSSION}

The TrussVR ${ }^{\odot}$ students were statistically significantly more successful at naming truss types and identifying specific trusses. However, Truss $\mathrm{VR}^{\mathcal{C}}$ did not change their attitudes towards trusses. As for overall skill differences, the evidence was inconclusive. However, 9 of the 15 skill measures were highest for TrussVR ${ }^{\odot}$. Moreover, three of the four retention scores were also highest for Truss $\mathrm{VR}^{\odot}$. As such, one could cautiously conclude that TrussVR ${ }^{\odot}$ had positive effects on learning. This is especially noteworthy when one recalls that participants only spent about 20 minutes doing the actual TrussVR ${ }^{\odot}$ lab modules (after a short 5-7 minute tutorial). It would appear that TrussVR ${ }^{\odot}$ may be an effective application of VR in teaching.

However, that might be an overstatement as what is not clear from our study is what lead to these differences. The Truss $\mathrm{VR}^{\odot}$ lab involved some testing of skills, as well as a potentially competitive game (the designing and testing of a bridge). Testing and gaming are both known to enhance learning, regardless of whether VR is used to create these opportunities $[11,12,14]$. Truss $\mathrm{VR}^{\odot}$ is aligned well with the philosophy of cognitive constructionists like Jean Piaget, wherein knowledge is actively constructed [4]. Similarly, the TrussVR ${ }^{\odot}$ software embraces the principles of constructivist learning environments that feature authentic tasks and reflective practice $[8,12]$. Processoriented guided-inquiry learning, or POGIL, is also based on a constructivist epistemology and has been shown to improve learning outcomes e.g. [20]. Likewise, problembased learning, or PBL, is clearly a feature of the bridge building module in Truss VR ${ }^{\odot}$ and PBL been shown to have similar benefits e.g. [18]. Having learners generate explanations for phenomena can be used to produce better long-term retention and application of knowledge [11]. This is exactly what happens in most of the modules in TrussVR ${ }^{\odot}$.

It would seem that the reason that the TrussVR ${ }^{\odot}$ group did better on naming and identifying truss types is that the Truss $\mathrm{VR}^{\odot}$ lab involved looking at and interacting with a variety of (named) truss types. The Pasco ${ }^{\odot}$ and No Lab groups did not have this experience, although ALL of the GE 124 students were introduced to the various truss types in lectures. What is especially interesting is that a couple of months later, those 6 minutes spent looking at and interacting with truss types made such a big difference in the ability of those students to both name and identify trusses. Such efficiency of learning is encouraging, but understanding what happened to bring it about requires further investigation (and confirmation).
In a similar vein, it is interesting to note that the Pasco $^{\odot}$ group did best (though not significantly so) on the Final Exam results for the truss question. More data is needed to draw a clear conclusion on this point, but given the increased time spent on meaningful calculations for the Pasco $^{\mathcal{C}}$ students (versus both of the other experimental groups), perhaps it is not a coincidence. This finding may become more significant with further data collection.

Testing can be even more effective at solidifying gains in learning $[11,12]$, and testing was potentially perceived as having been built into each of the modules in the firstyear Truss $\mathrm{VR}^{\odot}$ lab. This testing, however, may have given an unfair advantage to Truss $\mathrm{VR}^{\odot}$ in this study as no testing was involved in the Pasco ${ }^{\odot}$ or No Lab groups. Testing is not an inherent advantage of VR or TrussVR ${ }^{\odot}$, but it was a feature of the lab that was constructed in TrussVR ${ }^{\odot}$ for this study. Future work could approach this issue with the goal of achieving more clarity on this key point.

During the development of Truss VR ${ }^{\odot}$, it was noted by a couple of beta-testers that TrussVR ${ }^{\odot}$ does not really make the most effective use of the third dimension i.e. trusses are $2 \mathrm{D}$, and space trusses are not (yet) included in TrussVR ${ }^{\odot}$. This critique is valid, which is why a desktop version of Truss VR ${ }^{\odot}$ may be a useful comparator in a subsequent study. If the advantages of Truss $\mathrm{VR}^{\odot}$ were maintained in such a comparison, it would support the idea of embodied cognition as a learning enhancer. It could also be easier in VR to iterate rapidly through testing cycles of a truss, as compared to a 2D surface interface, so biometrics would still need to be monitored. Indeed, since biometric data was recorded during each of the TrussVR ${ }^{\odot}$ participant's VR time, one of the factors to examine will be whether more experimental iterations lead to better performance e.g. with the bridge design. However, the participants in this pilot study did not have much time to iterate on this task, so this question may need to wait for more data in the coming year.

While the details of these discussion points are important and do need to be resolved, it is equally clear that the future is bright for VR in empowering engineering education. Hardware and software capabilities continue to improve rapidly, which fuels more realistic virtual environments. Already, full experimental labs are being simulated in VR [17]. Similarly, the boundless promise of virtual prototyping in product, structural, process, and mechanical design is beginning to be realized e.g. $[1,15]$.

\section{FUTURE WORK}

This paper has highlighted all of the quantitative data gathered from the three surveys that were employed in this pilot study. Still to be analyzed are the following data sets: biometric data from TrussVR $^{\odot}$, qualitative answers common to the three surveys, and qualitative answers concerning VR asked just of the TrussVR ${ }^{\odot}$ participants. These will be the immediate priorities in future work. 
While this pilot study provided encouraging results for VR, more data points are required before the effects of using Truss $\mathrm{VR}^{\mathcal{O}}$ as a lab experience become clear. As such, we plan to carry out another data collection this Fall with first-year students, refining our methods based on learnings from this pilot study. Changes will include longer playing time on Truss $\mathrm{VR}^{\odot}$ to make for a fairer comparison with the 2-3 hour $\operatorname{Pasco}^{\circ}$ lab. One way to facilitate this is to provide a video of the Truss $V^{\odot}{ }^{\odot}$ tutorial before students actually go through the tutorial in VR, in the hopes that this will speed up the rate at which participants complete the VR tutorial. Changes may also involve employing two new versions of Truss $\mathrm{VR}^{\odot}$ labs i.e. one focused on testing activities and another on play, as well as a desktop analogue to Truss $\mathrm{VR}^{\odot}$ to deal with the VR novelty factor. As well, for all three tests (Pre, Post, and Distant-Post) in the pilot study, participants answered three of each type of skill-based question. These were isomorphic across tests. However, three of each type may have been too limited in resolution. Four or five of each will be included in the subsequent study. Nevertheless, efforts will still be made to shorten the Post survey to get better compliance and to decrease attrition. Finally, keeping in mind that we have not yet completed the analyses of the biometric or qualitative open-text questions in the pilot study, these yet-to-be-analyzed responses may provide further insights into what we should ask, and how we should ask it, in the future.

As a third priority, we may also look at the effects of using TrussVR ${ }^{\odot}$ in upper year structural engineering classes. Such a lab experience was already developed and deployed this past year, but the outcomes were not studied.

As a fourth project for future work, we are in the process of developing another piece of educational VR software that will go through the same efficacy review process. The results, general and specific, will eventually be compared to those from TrussVR ${ }^{\odot}$.

\section{Acknowledgements}

The authors would like to thank Ron and Jane Graham for their moral and financial support of this project, without which it would not have occurred. Likewise, we want to thank and recognize Tod Baudais and Bruce Cory of Sprockety Ventures Inc, and Ian Stavness of University of Saskatchewan Computer Science, for programming TrussVR $^{\odot}$. In developing TrussVR ${ }^{\odot}$, Bruce Sparling played an important role as a structural engineering consultant. Richard Heese was very helpful as tech support during the study, and in carrying out this study, Jim Bugg was vitally helpful as the Coordinator of GE 124 Mechanics I (Statics). We would also like to thank Stan $\mathrm{Yu}$ for his suggestions on how to complete the statistical analysis, and Yasi Delkash and Amir Ravanbod for their work as lab supervisors during the VR sessions.

\section{References}

[1] Abdul-Hadi G. Abulrub, Alex N. Attridge, and Mark A. Williams, "Virtual Reality in Engineering Education", Proceedings of the 2011 IEEE Global Engineering Education Conference, Amman, Jordan, pp. 751-757, April 2011.

[2] John T. Bell, and H. Scott Fogler, "Ten Steps to Developing Virtual Reality Applications for Engineering Education", American Society for Engineering Education 1997 Annual Conference Proceedings, Session 3213, Milwaukee, WI, 1997.

[3] C.C. Bonwell, and J.A. Eison, "Active Learning Creating Excitement in the Classroom", ASHEERIC Higher Education Report No. 1, George Washington University, Washington, DC, 1991.

[4] Grant Cooper, and Li Ping Thong, Implementing Virtual Reality in the Classroom: Envisaging Possibilities in STEM Education. In: STEM Education; An Emerging Field of Inquiry, Tasos Barkatsas, Nicky Carr and Grant Cooper (eds.), Brill Sense, Boston, pp. 61-73, 2019.

[5] Chelsea Ekstrand, Ali Jamal, Ron Nguyen, Annalise Kudryk, Jennifer Mann, and Ivar Mendez, "Immersive and interactive virtual reality to improve learning and retention of neuroanatomy in medical students: a randomized controlled study", The Canadian Medical Association Journal (OPEN), Vol. 6, No. 1, pp. E103-E109, 2018.

[6] Laura Freina, and Michela Ott, "A Literature Review on Immersive Virtual Reality in Education: State of the Art and Perspectives", Proceedings of eLearning and Software for Education (eLSE), Bucharest, April 23-24, 2015.

[7] Nancy Hubing, David B. Oglesby, Timothy A. Philpot, Vikas Yellamraju, Richard H. Hall, and Ralph E. Flori, "Interactive Learning Tools: Animating Statics", Proceedings of the 2003 American Society for Engineering Education Annual Conference \& Exposition, Session 2368, 2003.

[8] David H. Jonassen, and Lucia Rohrer-Murphy, "Activity theory as a framework for designing constructivist learning environments", Educational Technology, Research and Development, Vol. 47, No. 1, pp. 61-79, March 1999

[9] Michael Karweit, "Enhanced learning through a 'virtual laboratory", Proceedings of the 2002 American Society for Engineering Education Annual Conference \& Exposition, Session 1520, 2002.

[10] Hannes Kaufmann, Dieter Schmalstieg, and Michael Wagner, "Construct3D: A Virtual Reality Application for Mathematics and Geometry Education", Education and Information Technologies, Vol. 5, No. 4, pp. 263-276, 2000. 
[11] Douglas P. Larsen, Andrew C. Butler, and Henry I. Roediger III, "Repeated testing improves long-term retention relative to repeated study: a randomised controlled trial", Medical Education, Vol. 43, pp. 1174$1181,2009$.

[12] Douglas P. Larsen, Andrew C. Butler, and Henry I. Roediger III, "Comparative effects of test-enhanced learning and self-explanation on long-term retention", Medical Education, Vol. 47, pp. 674-682, 2013.

[13] J.H. Madden, A.S. Won, J.P. Schuldt, B. Kim, S. Pandita, Y. Sun, T.J. Stone, and N.G. Holmes, "Virtual Reality as a Teaching Tool for Moon Phases and Beyond", 2018 Physics Education Research Conference, 4 pages, 2018.

[14] Zahira Merchant, Ernest T. Goetz, Lauren Cifuentes, Wendy Keeney-Kennicutt, and Trina J. Davis, "Effectiveness of virtual reality-based instruction on students' learning outcomes in K-12 and higher education: a meta-analysis", Computers \& Education, Vol. 70, pp. 29-40, 2014.

[15] John I. Messner, Sai C.M. Yerrapathruni, Anthony J. Baratta, and Vaughn E. Whisker, "Using Virtual Reality to Improve Construction Engineering Education", Proceedings of the 2003 American Society for
Engineering Education Annual Conference \& Exposition, Session 1121, 2003.

[16] Veronica S. Pantelidis, "Virtual Reality and Engineering Education", Computer Applications in Engineering Education, Vol. 5, No. 1, pp. 3-12, 1997.

[17] Veljko Potkonjak, Michael Gardner, Victor Callaghan, Pasi Mattila, Christian Guetl, Vladimir M. Petrovic, and Kosta Jovanovic, "Virtual laboratories for education in science, technology, and engineering: a review", Computers \& Education, Vol. 95, pp. 309-327, 2016.

[18] Michael Prince, "Does Active Learning Work? A Review of the Research", Journal of Engineering Education, pp. 223-231, July 2004.

[19] Henry L. Roediger III, and Jeffrey D. Karpicke, "The Power of Testing Memory: Basic Research and Implications for Educational Practice", Perspectives on Psychological Science, Vol. 1, No. 3, pp. 181-210, 2006.

[20] Thea Vanags, Kristen Pammer, and Jay Brinker, "Processoriented guided-inquiry learning improves long-term retention of information", Adv. Physiol. Educ., Vol. 37, pp. 233-241, 2013. 